\title{
Núcleos de Apoio à Saúde da Família: análises estratégica e lógica
}

\author{
Family Health Support Centers (Nasf): strategic and logical analysis
}

Patrícia lacabo', Juarez Pereira Furtado1

DOI: 10.1590/0103-1104202012606

RESUMO Profissionais dos Núcleos de Apoio à Saúde da Família frequentemente possuem questões relacionadas ao próprio modelo tecnoassistencial que sustenta estes núcleos, indicando a necessidade de investigações de sua estratégia e lógica interna. Realizou-se pesquisa avaliativa utilizando estudo de caso, observação participante, grupos focais e análise documental. Observou-se que os Núcleos de Apoio à Saúde da Família expandem o escopo da atenção e possibilitam incorporação de novos conhecimentos pelas equipes da Atenção Básica, pertinentes às suas principais estratégias. No entanto, a pertinência das parcerias estratégicas esbarra na necessidade de cooperação entre as duas equipes, o que pode não se concretizar ou se concretizar parcialmente. A análise de sua lógica de funcionamento evidencia impasses na efetivação da colaboração profissional e no dilema entre atuar como generalistas ou especialistas na Atenção Básica.

PALAVRAS-CHAVE Avaliação em saúde. Estratégia Saúde da Família. Relações interprofissionais.

ABSTRACT Professionals of the Family Health Support Centers (Nasf) often have questions related to the techno-assistance model that supports these centers, indicating the need for investigations of their strategy and internal logic. Evaluative research was carried out using case study, participant observation, focus groups and documentary analysis. It was observed that Family Health Support Centers expand the scope of care and allow the incorporation of new knowledge by Primary Care teams, pertinent to their main strategies. However, the relevance of strategic partnerships runs counter to the need for cooperation between the two teams that may not materialize or be partially done. The analysis of its functioning logic shows deadlocks in the effectiveness of professional collaboration and in the dilemma between acting as generalists or specialists in Primary Care.

KEYWORDS Health evaluation. Family Health Strategy. Interprofessional relations. 


\section{Introdução}

O Núcleo de Apoio à Saúde da Família (Nasf) representa a incorporação, pela Atenção Básica $(\mathrm{AB})^{\mathbf{1}, \mathbf{2}}$, de novos saberes oriundos de especialidades da saúde por meio do apoio ofertado às equipes de Saúde da Família (eSF), visando à ampliação da resolutividade da $\mathrm{AB}^{\mathbf{1 , 3}}$. $\mathrm{A}$ proposta formulada em 2008 teve adesão em vários estados ${ }^{2}$, contando com mais de 5 mil equipes cadastradas no Ministério da Saúde (MS), em dezembro de $2017^{4}$. Apesar deste crescimento numérico, o cenário apresentado na literatura científica é de enfrentamento de desafios para sua consolidação, inclusive em aspectos centrais, como o apoio matricial5.

Sob influência de entidades profissionais, áreas técnicas do MS e de grupo de pesquisa ligado ao Departamento de Saúde Coletiva da Universidade Estadual de Campinas (Unicamp) ${ }^{6}$, referenciais de apoio matricial e clínica ampliada, aliados às Redes de Atenção à Saúde (RAS), passaram a balizar a prática nesses núcleos $\mathbf{7 , 8}$. Tal organização da assistência demanda arranjos, entre as equipes, significativamente distintos da prática corrente ${ }^{8}$. Diferentes e mesmo divergentes concepções sobre matriciamento, trabalho interdisciplinar e intersetorial, além de descompasso entre a atuação do Nasf e as expectativas das eSF, evidenciam problemas que tangenciam o modelo tecnoassistencial destes núcleos 9 ,10.

Entre as principais questões dos profissionais desses núcleos, encontra-se explícita dificuldade em implementá-los, ou seja, transpor os seus princípios para a prática ${ }^{11}$. Tal situação torna a análise das concepções, as hipóteses teóricas e a implementação dos Nasf tão importantes quanto seus possíveis resultados e efeitos - aspectos tradicionalmente abordados em avaliação. Assim, as chamadas análises estratégica e lógica - que podem integrar processos avaliativos e considerar aspectos da própria formulação da proposta $^{12,13}$, conforme vem sendo feito por alguns estudos ${ }^{\mathbf{1 4 - 1 6}}$ - permitiriam abordar os Nasf no que concerne à sua constituição mais essencial, como seu modelo tecnoassistencial, suas premissas e hipóteses.

A Análise Estratégica (AE) pretende determinar a coerência entre os objetivos da intervenção e os problemas a ela endereçados. Para isto, considera-se como objetos de análise a escolha do problema, a definição dos objetivos e a pertinência das parcerias para a implementação de uma dada iniciativa ${ }^{13}$. A AE avalia se há correspondência entre as ações propostas em um programa e o contexto epidemiológico, político, sanitário e financeiro ${ }^{15}$. A Análise Lógica (AL), por sua vez, considera a adequação entre os objetivos da proposta $\mathrm{e}$ os meios implantados para atingi-los ${ }^{\mathbf{1 2}}$, verificando a coerência entre um programa, seus objetivos e os fluxos estabelecidos para obter os resultados ${ }^{\mathbf{1 4}}$.

A mudança na Política Nacional de Atenção Básica (PNAB) ${ }^{17}$ atingiu os 'Núcleos de Apoio à Saúde da Família' (Nasf), que, entre outras coisas, passaram a ser nomeados 'Núcleos Ampliados de Saúde da Família e Atenção Básica' (Nasf-AB). Esta mudança reaproxima os núcleos de seus precursores, os 'Núcleos de Atenção Integral na Saúde da Família' (Naisf), que eram voltados à assistência direta aos usuários ${ }^{7}$. Nesse momento, seria prematuro analisar as consequências dessas mudanças, no entanto, os três distintos nomes refletem indefinições importantes sobre a natureza, o objeto e o modus operandi desses serviços, desde a sua criação. Tal indefinição foi observada em significativo número de agentes envolvidos com a iniciativa ${ }^{11}$, reforçando a necessidade de pesquisas com foco na investigação de aspectos essenciais da proposta - como a aposta estratégica, articulação e implementação de suas ações - a partir de experiências práticas que subsidiem as análises estratégica e lógica citadas.

\section{Material e métodos}

O caso é constituído por dois Nasf (Nasf A e Nasf B) de município da região metropolitana de São Paulo, com aproximadamente 450 mil habitantes ${ }^{\mathbf{1 8}}$, dividido em cinco territórios 
de saúde e com 23 Unidades Básicas de Saúde (UBS), sendo 12 Unidades de Saúde da Família (USF) e 11 compostas simultaneamente pelos modelos tradicional e de Estratégia Saúde da Família (ESF). As 12 USF têm apoio dos 5 Nasf implantados em 2015. Os dois Nasf constituíram amostra intencional, caracterizados pela gestão do município como: 1) aquele que mais se aproximava da proposta oficial do MS; e 2) que apresentava mais desafios para a sua implantação.

A triangulação de métodos ${ }^{\mathbf{1 9}, 20}$ permitiu a agregação de diferentes fontes sobre a iniciativa, sendo constituída de: a) revisão integrativa da literatura; b) observação participante; c) Grupos Focais (GF); e d) análise dos Boletins de Produção Ambulatorial (BPA) relativos a junho, setembro e outubro de 2016. Não houve coleta dos BPA nos meses de julho e agosto, pois os núcleos sofreram reestruturação de atribuições nesse período. A composição do corpus considerou a saturação teórica ${ }^{21}$, e a coleta de dados se deu no período de maio a outubro de 2016.

A revisão bibliográfica possibilitou a identificação dos principais pontos em questão no Nasf, e a observação participante se deu pela imersão no contexto natural em que se desenvolvem as ações dos serviços analisados ${ }^{22}$. Foram realizadas 180 horas de observação, registradas em diários de campo, e três GF (com cada um dos dois Nasf e, separadamente, com profissionais da $\mathrm{AB}$ ), abordando questões do modelo tecnoassistencial e do cotidiano do Nasf. A elaboração dos roteiros dos GF recebeu subsídios da observação participante. Os BPA dos dois Nasf (relativos a junho, setembro e outubro de 2016) permitiram especificar e objetivar os procedimentos realizados pelos profissionais. A partir das noções de análises estratégica e lógica, foi realizada leitura sistemática do material empírico.

O presente estudo foi aprovado no Comitê de Ética em Pesquisa sob o número 0861/2015. Foi entregue a todos os participantes o Termo de Consentimento Livre e Esclarecido para sanar dúvidas sobre a pesquisa.

\section{Caracterização do Núcleo de Apoio à Saúde da Família}

Os modos como são concebidos e concatenados recursos, atividades e resultados dos Nasf, com base em documentos do MS ${ }^{11}$, estão sistematizados por meio de Modelo Lógico (figura 1). No entanto, a linearidade desse fluxo idealizado não poderia estabelecer, a priori, as tensões e resistências a que estão sujeitas as articulações interprofissional e intersetorial, entre outras, para o êxito desses núcleos. Nesse sentido, o estudo empírico objetivou identificar potencialidades e entraves à transposição da proposta para um meio específico, com base nos dois Nasf acompanhados (quadro 1). Sua forma de organização e seu funcionamento serão abordados a seguir, em um esforço de síntese que priorizou a descrição de aspectos centrais e eventualmente problemáticos, ligados aos interesses do presente estudo, de analisar sua lógica e sua estratégia. 
Quadro 1. Caracterização das equipes dos Nasf A e B

\begin{tabular}{|c|c|c|}
\hline & Nasf A & Nasf B \\
\hline Composição da equipe & $\begin{array}{l}\text { Assistente social (1), educador físico } \\
\text { (1), fisioterapeuta (1), fonoaudiólogo } \\
\text { (1), nutricionista (1), psicólogo (2) }\end{array}$ & $\begin{array}{l}\text { Assistente social (1), educador físico } \\
\text { (1), fisioterapeuta (1), fonoaudiólogo } \\
\text { (1), nutricionista (1), psicólogo (2) }\end{array}$ \\
\hline Carga horária semanal & 240 horas (modalidade 1) & 230 horas (modalidade 1) \\
\hline № de eSF apoiadas & 14 & 12 \\
\hline № de USF apoiadas & 3 & 3 \\
\hline Formação da equipe & $\begin{array}{l}6 \text { profissionais da rede do município; } \\
1 \text { de processo seletivo para o Nasf }\end{array}$ & $\begin{array}{l}3 \text { profissionais da rede do município; } \\
4 \text { de processo seletivo para o Nasf }\end{array}$ \\
\hline Vínculo empregatício & 6 por OS; 1 estatutário & 4 por OS; 3 estatutários \\
\hline
\end{tabular}

Fonte: Elaboração própria.

Nasf: Núcleo(s) de Apoio à Saúde da Família; eSF: equipe(s) de Saúde da Família; USF: Unidade(s) de Saúde da Família.

Figura 1. Modelo Lógico do Núcleo de Apoio à Saúde da Família.

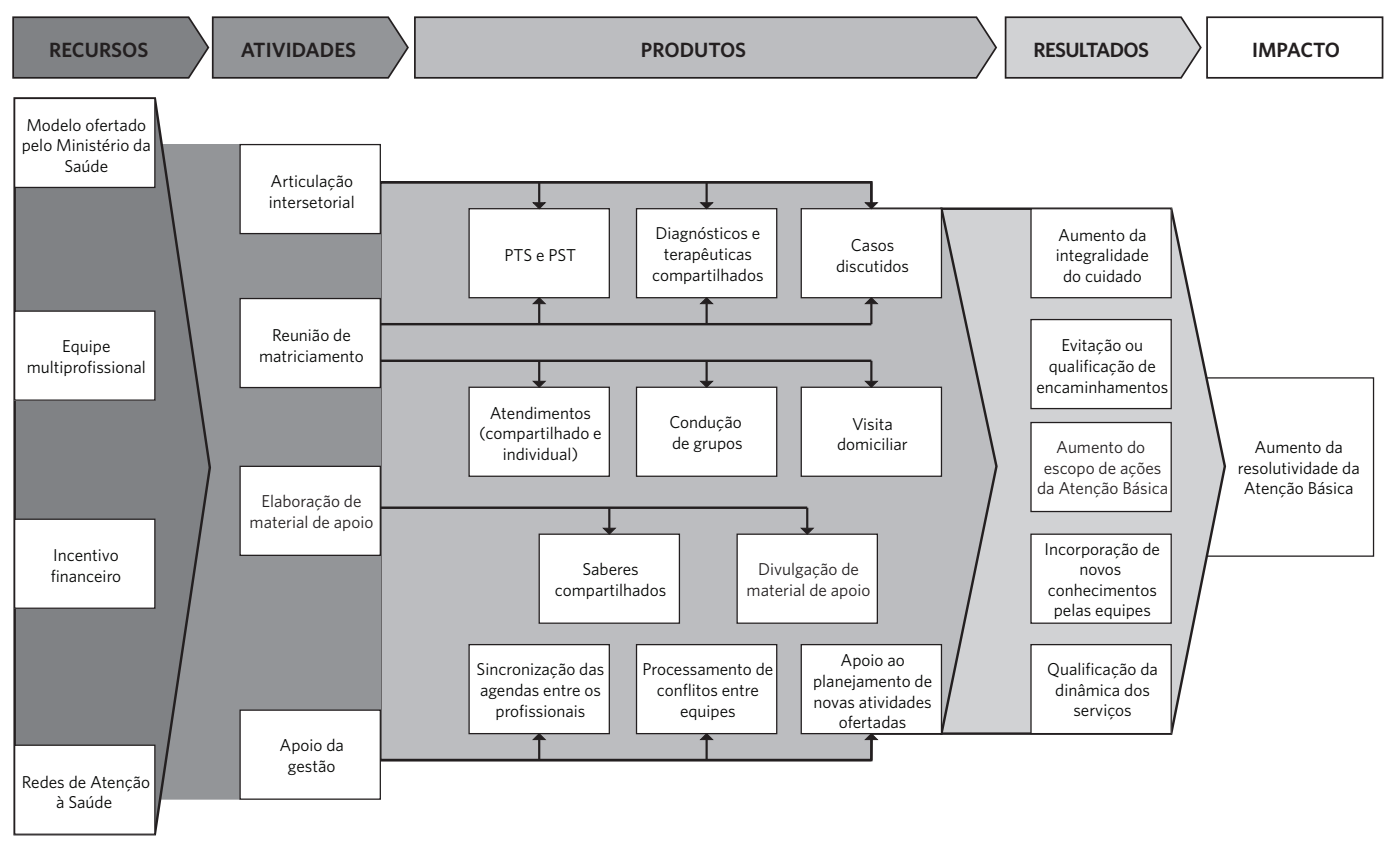

Fonte: Correia PCl, Goulart PM, Furtado JPn.

PTS: Projeto Terapêutico Singular; PST: Projeto de Saúde no Território.

A organização da agenda de trabalho de ambos os Nasf se baseia na presença de duplas de profissionais do núcleo nas reuniões das eSF. Se a dupla não representar áreas afins às do caso, este é levado à reunião da equipe do Nasf. Esta situação, na visão de alguns profissionais, apresenta o risco de reprodução da tradicional 'passagem de casos' ou 'encaminhamentos', com distanciamento e demora no atendimento.

No entanto, o rompimento de práticas tradicionais é visto como desafio. Profissionais do Nasf se sentem sobrecarregados ao ter que ensinar as eSF a discutir casos e compartilhar diagnósticos e terapêuticas, o que frequentemente requer diversas etapas e apresenta retorno 
lento. Há o entendimento de que a gestão não exige que as eSF trabalhem 'com' o Nasf:

Na proposta do Ministério, é muito lindo. E funcionaria muito bem, se todo mundo tivesse aberto pra essa proposta, mas quem tá aberto pra proposta é só a gente. (Profissional do Nasf).

[...] sempre é a gente que tem que conquistar. (Profissional do Nasf).

Alguns episódios denotam problemas de articulação ou mesmo conflitos entre os núcleos e as eSF, como prescindir da presença do Nasf nas reuniões de matriciamento entre Centro de Atenção Psicossocial (Caps) e eSF ou, explicitamente, não convidar os profissionais do Nasf para eventos comemorativos internos à USF. Mesmo o necessário encontro entre as equipes é, às vezes, comprometido quando as eSF não ajustam seus horários de reuniões para possibilitar a participação de todos os profissionais do Nasf.

Mas os encontros podem ser dificultados pelos próprios núcleos. Com o intuito de otimizar o tempo, os profissionais do Nasf participam apenas de parte da reunião das eSF, restringindo possibilidades de matriciamento e priorizando os chamados 'casos do Nasf' - situações de impasse para a eSF, constituídas de casos cuja resposta requer ações especialmente complexas. Para os trabalhadores do núcleo, as críticas sintetizadas na afirmação de que " $O$ Nasf não funciona", vinda da eSF, se devem à frustração dos colegas pela relativa demora no atendimento e/ou resposta a alguns casos, pela dificuldade de assumir conjuntamente a sua condução e pela impossibilidade de os núcleos solucionarem situações extremamente difíceis.

A insuficiente colaboração entre Nasf e eSF pode ser ilustrada quando profissionais desta última não compartilham informações sobre casos ou, por alguma razão, se recusam a realizar atendimentos conjuntos: "A gente fala compartilhada, já fica aquele silêncio assim" (Profissional do Nasf). Ou esbarram na expectativa dos profissionais das eSF de atuação tradicional pelos especialistas: " $E$ difícil você fazer matriciamento com o outro que não quer compartilhar, (...) ele [médico da eSF] só quer passar o caso" (Profissional do Nasf).

A ausência de formação acadêmica para o exercício do matriciamento pelos integrantes do Nasf, a formação em saúde calcada na assistência curativa e a mudança repentina das unidades tradicionais para o modelo de ESF, juntamente à 'cultura do encaminhamento', são elementos considerados, pelos profissionais do Nasf, que explicam a predileção das eSF pela passagem de casos e por encaminhamentos.

Os profissionais do núcleo se consideram poupados pela posição de matriciadores, ao não serem acionados pelas urgências cotidianas, como são os colegas da eSF (equipes de referência):

[...] a gente tá aqui na reunião de equipe nossa, de Nasf, já vem gente bater na porta, né? Imagina com um enfermeiro e com um médico, que toda hora vem alguém [...] 'Fulano, tem uma receita aqui! Ó, o acolhimento! Ó, sua gestante tá aí fazendo barraco!'. É muito complicado [...] a gente ainda é privilegiado de conseguir ter esses momentos, a gente tranca a porta e deixa o bicho pegar ali fora [...]. (Profissional do Nasf).

Há concentração de demanda em determinadas categorias profissionais, principalmente na psicologia e na nutrição, mais reconhecidas pelos profissionais das eSF, que acabam sendo mais demandadas por atendimentos especializados de seu núcleo profissional (tabela 1). Neste processo de afunilamento da atuação de profissionais às suas áreas de origem, podem também ser privilegiados determinada área e/ou público (infantil, gestante, idoso, entre outros), de acordo com a especialidade, experiência ou afinidade de um dado profissional. Ou o direcionamento, pela gestão, do exercício específico de uma área, como destinar ao serviço social atividades ligadas à isenção tarifária. Na tabela 1, observa-se a distribuição das atividades realizadas pelos dois Nasf, de acordo com cada categoria profissional. 
Tabela 1. Distribuição das atividades realizadas pelos profissionais das equipes Nasf ${ }^{\star} A$ e B, nos meses de junho, setembro e outubro de 2016, a partir dos dados do BPA.

\begin{tabular}{|c|c|c|}
\hline Profissionais & Atividades & Distribuição (\%) \\
\hline \multirow{4}{*}{$\begin{array}{l}\text { Assistente } \\
\text { social }\end{array}$} & Atendimento individual & 68,9 \\
\hline & Atividade educativa e orientação em grupo & 21,9 \\
\hline & Atendimento domiciliar & 6,3 \\
\hline & Terapia em grupo & 3 \\
\hline \multirow[t]{3}{*}{ Educador físico } & Atividade educativa e orientação em grupo & 40 \\
\hline & Prática corporal em grupo & 45,5 \\
\hline & Oficina terapêutica em grupo & 14,5 \\
\hline \multirow[t]{5}{*}{ Fisioterapeuta } & Atendimento individual & 19,5 \\
\hline & Atividade educativa e orientação em grupo & 32,1 \\
\hline & Prática corporal em grupo & 25,3 \\
\hline & Atendimento domiciliar & 23,2 \\
\hline & Avaliação antropométrica & 0 \\
\hline \multirow[t]{5}{*}{ Fonoaudiólogo } & Atendimento individual & 44,5 \\
\hline & Atividade educativa e orientação em grupo & 4,1 \\
\hline & $\begin{array}{l}\text { Avaliação de linguagem escrita, leitura e oral; e miofuncional de sistema esto- } \\
\text { matognático }\end{array}$ & 29,5 \\
\hline & Atendimento domiciliar & 6,2 \\
\hline & Terapia em grupo & 15,8 \\
\hline \multirow[t]{9}{*}{ Nutricionista } & Atendimento individual & 43,8 \\
\hline & Atividade educativa e orientação em grupo & 28,5 \\
\hline & Atendimento domiciliar & 5,5 \\
\hline & Avaliação antropométrica & 22,1 \\
\hline & Psicólogo & 69,1 \\
\hline & Atividade educativa e orientação em grupo & 17,5 \\
\hline & Atendimento domiciliar & 4,2 \\
\hline & Terapia em grupo & 7,7 \\
\hline & Oficina terapêutica em grupo & 1,5 \\
\hline \multirow[t]{5}{*}{ Equipe Nasf } & Atendimento individual & 50,8 \\
\hline & Atividade educativa e orientação em grupo & 23 \\
\hline & Oficinas, terapias e práticas corporais em grupo & 12,1 \\
\hline & Atendimento domiciliar & 6,6 \\
\hline & Avaliações específicas do núcleo de conhecimento & 7,5 \\
\hline
\end{tabular}

Atividades como atendimento domiciliar, oficinas terapêuticas e práticas corporais são realizadas em colaboração com os Agentes Comunitários de Saúde (ACS) e, em menor número, com outros profissionais da USF. Os atendimentos individuais são realizados pelos profissionais do Nasf e, raramente, compartilhados com outros profissionais das eSF. No entanto, a tentativa de tomar o caso para si pode não ser resolutiva devido ao pouco tempo que os profissionais do Nasf dispõem para cada unidade apoiada. Mesmo casos solucionados podem ser fontes de frustração para estes profissionais, que consideram a baixa abrangência de seu trabalho frente à elevada demanda. Para a eSF e o Nasf, o apoio deveria ser distribuído em menor número de equipes por núcleo.

Os grupos conduzidos pelo Nasf, em sua maioria, são voltados a uma queixa ou doença 
específica, como de linguagem e fala, dislipidemias, dores crônicas, e não contam com a participação dos profissionais das eSF, por falta de interesse destes ou pela restrição, por parte da gestão, que preza pela produção das atividades obrigatórias. Por sua vez, os grupos conduzidos pelas eSF não possuem participação do núcleo e parecem responder às atribuições dos profissionais das eSF previstas na legislação. Os grupos terapêuticos e as atividades de prevenção e promoção à saúde não são planejados conjuntamente entre eSF e Nasf.

Atendimentos individuais e atividades de educação permanente do Nasf subsidiam a eSF na condução de casos ou no enriquecimento de atividades típicas desta, como o programa de educação em saúde voltado ao aleitamento materno. Nesse último caso, o Nasf incentivou as eSF a revisarem suas ações com as gestantes e compartilharem visitas domiciliares com os núcleos. Podem-se observar efetivas contribuições do núcleo qualificando discussões em reuniões da eSF, como aquelas ligadas à reforma psiquiátrica ou a melhor resposta às escolas (ou ao Conselho Tutelar) em situações limítrofes entre o normal e o patológico no comportamento de crianças, por exemplo.

Quando atendimentos individuais e grupos são compartilhados, observa-se abordagem ampliada daqueles casos, como o reconhecimento de médicos das eSF frente aos benefícios da atuação conjunta:

[...] ela [profissional do Nasf] acha que o matriciamento ampliou o olhar do médico porque ele aceitou discutir o caso depois da VD [Visita Domiciliar - neste caso, compartilhada] e evoluir no prontuário juntos. [...] ela [profissional do Nasf] disse que encontrou com outra médica da unidade, que cobrou essas VDs compartilhadas também. (Trecho do diário de campo de 26 de julho de 2015).

Observa-se que alguns profissionais do Nasf propõem ações que visam ao cuidado integral e tentam trabalhar diante de uma RAS pouco articulada. Esta característica é reconhecida pelos demais profissionais da USF:

[...] elas são inconformistas! É só isso que a gente vai fazer? Não! Vamos fazer mais! (Gerente de uma das USF apoiadas).

[...] não é a rede que funciona, elas funcionam bem, elas fazem funcionar. E se elas faltassem? (Médica de uma das eSF apoiadas).

Alguns profissionais da USF consideram o Nasf resolutivo e reconhecem que o núcleo ajuda as eSF a discutir casos e a desenvolver aspectos específicos de sua missão:

[...] com o Nasf, as equipes aprenderam realmente a se ver como PSF [Programa Saúde da Família] [...] [o Nasf e o supervisor do Mais Médicos] começou a ensinar pr'a gente o que era discutir caso. Que na discussão de um caso, todo mundo da equipe era importante. (Gerente de uma das USF apoiadas).

Ainda que com dificuldades, a constante interação entre Nasf e eSF parece exigir abertura para o cuidado integral em saúde, incorporando novos conhecimentos às equipes. $\mathrm{O}$ leque de atribuições do núcleo amplia a oferta de ações na $A B$ e qualifica encaminhamentos para serviços e demandas de outros setores. Por outro lado, observam-se questões, como a tensão entre a atuação generalista e específica, além das dificuldades para a colaboração interprofissional, constituindo fatores que podem comprometer a implantação e o desenvolvimento da proposta, como discutirá a seguir.

\section{Discussão}

\section{Análise Estratégica}

A AE considera a intervenção sob três perspectivas: a escolha do problema; a definição dos objetivos da intervenção e sua população-alvo; 
e as parcerias estratégicas ${ }^{13}$. No caso do Nasf, o problema escolhido foi a baixa resolutividade e integralidade das ações da $\mathrm{AB}$, no que tange às especialidades. A ampliação do conhecimento e da gama de intervenções das eSF, por meio de apoio matricial do Nasf, foi o principal objetivo estabelecido, sendo tanto pacientes como colegas trabalhadores suas populações-alvo. Finalmente, equipes da $\mathrm{AB}$ e gestores distritais e municipais integram grupo de potenciais parceiros da iniciativa.

Destinada a resolução de $80 \%$ dos problemas em saúde ${ }^{17}$, é de se esperar que a atenção cotidiana na $\mathrm{AB}$ se depare com situações demandando conhecimentos que extrapolam os limites das eSF. A constituição dos grupos a partir de demanda reprimida nas unidades e os casos de elevada complexidade - os chamados 'casos do Nasf' - ilustram a situação e apontam para a pertinência dos núcleos, à medida que permitem romper com o modelo de cuidado hospitalocêntrico e o enfrentamento de problemas dos territórios nos quais estão inseridos. Nessa direção, pôde-se observar a qualificação de encaminhamentos e dos modos de apresentar demandas a outros setores, o que levou ao aprimoramento da construção e condução dos casos, justamente por meio da ampliação dos conhecimentos das eSF e de sua capacidade de intervenção.

No entanto, para a ampliação de saberes e da capacidade de intervenção, pressupõe-se formato de interação entre Nasf e eSF que coloca esta última na condição simultânea de clientela-alvo e parceira. Tal condição contrasta com o formato da passagem de caso e atendimento individual feito pelo especialista - ambos fortemente arraigados nas expectativas e práticas das equipes envolvidas - e que constitui obstáculo evidente à proposta Nasf. Neste sentido, a estratégia de ampliar o conhecimento e escopo dos integrantes das equipes da $\mathrm{AB}$ deve levar em conta sua bidirecionalidade, visto tratar-se de ação condicionada à efetiva cooperação da clientela-alvo para o seu sucesso, por meio do estabelecimento de plena parceria entre núcleos e AB. Poderia residir aí especial fragilidade na concepção estratégica dos Nasf, na medida em que esses núcleos detêm baixa governabilidade sobre as eSF e acumulam poucos instrumentos, tanto na formação individual de seus integrantes quanto nos modelos tecnoassistenciais da RAS, para fazerem frente à cultura pouco colaborativa entre disciplinas, profissões e instituições, e, desta forma, promoverem a ampliação do conhecimento e conjunto de ações na AB. Em outras palavras, a estratégia da proposta implica abertura e permeabilidade à cooperação, que não estão garantidas no encontro entre profissionais de ambas as equipes.

Em outra perspectiva, o formato do modelo assistencial dos Nasf dá margem a situações de certo isolamento, como é o caso da pressão assistencial, suportada pela eSF. Neste caso, os profissionais do Nasf sentem-se até privilegiados por não serem requisitados pela intensa demanda das USF, poupados pela intermediação a que estão relegados. Nesta perspectiva, a lógica profissional da diferenciação acaba prevalecendo em detrimento da colaboração ${ }^{23}$ e poupando os trabalhadores dos Nasf de mais contato e comprometimento com as práticas da $\mathrm{AB}$.

Outra questão estratégica a ser considerada é o fato de o Nasf integrar a AB e, apesar de constituído por especialistas, ser requisitado a desenvolver atividades de caráter generalista, como ações voltadas ao território e iniciativas de promoção. Esta característica, entre outras questões, pode ocasionar superposição entre as duas equipes e distanciar os matriciadores de seu núcleo de competência ${ }^{24}$.

O desenvolvimento das políticas de saúde do Sistema Único de Saúde (SUS) se dá de maneira centralizada e percorre, verticalmente, diferentes instâncias até chegar aos serviços municipais ${ }^{25}$. Desta forma, os gestores municipais e distritais são fundamentais para articulação com os demais níveis federativos e para atuação alinhada com os princípios do SUS, no desenvolvimento de ações de saúde do Nasf no território. No entanto, apesar da pertinência das parcerias estratégicas estabelecidas para o Nasf, há conflito na vinculação 
empregatícia por Organização Social (OS). Os profissionais ficam submetidos à métrica quantitativa de procedimentos destas organizações, que induz a práticas desarticuladas e fragmentadas, deixando o papel de intervenção do gestor municipal limitado.

\section{Análise Lógica}

A AL considera a razoabilidade das hipóteses teóricas e a coerência e pertinência dos meios implementados para alcançar os objetivos da intervenção, o que pode ser facilitado pelo uso de modelização ${ }^{\mathbf{1 2}}$. No estudo empírico, foi possível identificar questões da validade pragmática, relativa à propriedade dos meios para o alcance dos objetivos da intervenção. As questões principais são o apoio matricial e a colaboração entre os profissionais.

$\mathrm{O}$ apoio matricial, referencial teórico-metodológico de orientação para o trabalho no Nasf, possui duas dimensões, a assistencial e a técnica-pedagógica. A dimensão assistencial, caracterizada por ação direta aos usuários com devolutiva da intervenção realizada para as equipes de referência ${ }^{26}$, foi mais frequentemente encontrada na prática do Nasf. A realização dos atendimentos especializados favoreceu a dinâmica entre as duas equipes em relação às expectativas das eSF de resolução dos casos encaminhados para o Nasf. Por outro lado, a prática dessa dimensão do apoio auxiliou os profissionais das eSF a compreenderem as atribuições das diferentes categorias profissionais do núcleo.

Para alguns gestores, o apoio matricial é entendido e reduzido à sua vertente assistencial, o que ocasionou cobranças de remodelação das equipes Nasf para atuarem com as eSF e gerou insatisfação dos matriciadores, explicitada no entendimento de que as eSF não eram cobradas para trabalhar 'com' o Nasf.

A dimensão técnico-pedagógica do apoio matricial, caracterizada por ações e apoio educativo ${ }^{26}$, se deu por meio de indução de reflexões e análises sobre ações isoladas, fragmentadas e centradas na doença. Em diversas situações, foram identificados obstáculos à realização de atividades compartilhadas e educativas. A abertura para o compartilhamento do trabalho era mais frequente entre profissionais que detêm menos poder no contexto institucional (como os ACS), que têm mais a ganhar do que a perder ${ }^{27}$.

A dubiedade entre pertencer ou não à $\mathrm{AB}$, entre atuar de acordo com a colaboração profissional ou a lógica profissional, é evidenciada pelo significativo volume de publicações cuja indagação central versa sobre o papel de uma dada categoria nesses núcleos. Curiosamente, no entanto, cada categoria profissional busca, no interior de si própria - em seu núcleo de competências e responsabilidades -, respostas sobre como atuar no Nasf, quando, na verdade, a resposta parece situar-se na articulação entre os diferentes profissionais especialistas e destes com as equipes de referência ${ }^{11}$.

Como dito anteriormente, o tipo de atividade proposta pelo Nasf se concentrava em ações do núcleo de saber de cada profissional, mas há que se considerar a existência de limites que qualquer saber estruturado encontrará, independentemente da infinidade de casos acompanhados, uma vez que se trata da prática na vida real e concreta ${ }^{8}$. Assim, sendo coletivas ou individuais, compartilhadas com as eSF ou especializadas, houve agregação de novas ofertas na $\mathrm{AB}$ e aumento de gradientes de interdisciplinaridade. Ainda que ponderassem sobre as dificuldades para ensinar as eSF a discutir casos, estas afirmações se sustentam, sobretudo, na constante busca pela troca de conhecimento entre eSF e Nasf, quer seja no matriciamento através das devolutivas de casos atendidos pelas especialidades, quer pela troca de informações, discussão de casos e compartilhamento de atividades entre os próprios profissionais do núcleo, contribuindo para o alcance das dimensões relacionais que influenciam a colaboração profissional23.

Ao mesmo tempo em que a conformação multiprofissional das equipes Nasf e o estabelecimento de espaços rotineiros de discussão, a partir de ações compartilhadas e de reflexão, 
potencializaram o fortalecimento de uma nova forma de organização do serviço, em determinados momentos, a baixa articulação entre as equipes Nasf e das USF levou a ações fragmentadas. A colaboração profissional permeia a dificuldade de transposição da interdisciplinaridade para a prática, o trânsito entre campo de atuação e núcleo de responsabilidades e a tensão entre a atuação generalista e a específica, reforçada pelas diretrizes oficiais. Considerando 'campo' como espaço estruturado de posições em que dominantes e dominados lutam pela manutenção e pela obtenção de determinadas posições, no caso da saúde e, mais especificamente, da $\mathrm{AB}$, o processo colaborativo poderia sofrer resistência justamente pelo receio de perda de capitais valiosos dos agentes, na medida em que o compartilham ${ }^{\mathbf{2 8}}$, voltado à preservação do território profissional. Assim, considera-se que a lógica de atuação do Nasf está produzindo práticas colaborativas, mas se defronta, constantemente, com aspectos não considerados pela política, como a dificuldade de transposição da proposta teórica de uma equipe multidisciplinar para atuação prática interprofissional colaborativa, e disputas inerentes a esse processo de horizontalidade das relações.

\section{Conclusões}

O modelo hegemônico de atenção à saúde, hospitalocêntrico e centrado no profissional de saúde, predomina na formação das diferentes profissões de saúde. Por outro lado, as diretrizes do Nasf orientam o trabalho no sentido da articulação interdisciplinar e intersetorial, do matriciamento e da integralidade nas ações de saúde, ou seja, somam esforços para romper com este modelo, em busca da $\mathrm{AB}$ como ordenadora de cuidados resolutivos e promotora de acesso à RAS. Observa-se que somente a inserção de uma equipe multiprofissional para atuar colaborativamente, entre si e com os demais profissionais da $\mathrm{AB}$, ampliando as ofertas em saúde, não é suficiente para o aumento da integralidade do cuidado.

Considera-se que o aumento da resolutividade da $\mathrm{AB}$ e a integralidade da atenção não serão alcançados somente com a exigência de um novo perfil profissional, orientado pela lógica da colaboração. Há necessidade de enfrentamento de outras questões, como a desarticulação da rede, a verticalização das relações, a escassez de profissionais qualificados, a sobrecarga de trabalho das eSF, a carência de serviços especializados e o conflito existente entre a necessidade de mudança do modelo biomédico e a submissão à métrica quantitativa de procedimentos das OS. Por fim, identifica-se a necessidade de criar mecanismos que exponham os núcleos e seus profissionais às demandas que pressionam diariamente os profissionais da $\mathrm{AB}$, ou seja, que se aumente a permeabilidade e porosidade dos Nasf ao cotidiano das eSF e da AB.

\section{Colaboradores}

Iacabo P (0000-0003-2457-0166)* contribuiu para a concepção do estudo, para o desenho metodológico, o trabalho em campo, para a produção dos dados, análise e discussão dos resultados, redação e revisão crítica do texto. Furtado JP (0000-0001-6605-1925)* contribuiu para a concepção do estudo, para o desenho metodológico, para a discussão dos resultados e revisão crítica do texto. 


\section{Referências}

1. Brasil. Ministério da Saúde. Portaria no 154 , de 24 de janeiro de 2008. Cria os Núcleos de Apoio à Saúde da Família - NASF; 2008. Diário Oficial da União. 25 Jan 2008.

2. Castro ALB, Machado CV. A política federal de atenção básica à saúde no Brasil nos anos 2000. Physis. 2012; 22(2):477-506.

3. Brasil. Ministério da Saúde. Portaria no 2488, de 21 de outubro de 2011. Aprova a Política Nacional de Atenção Básica, estabelecendo a revisão de diretrizes e normas para a organização da Atenção Básica, para a Estratégia Saúde da Família (ESF) e o Programa de Agentes Comunitários de Saúde (PACS). Diário Oficial da União. 22 Out 2011.

4. Datasus. Sistema de Cadastro Nacional de Estabelecimentos de Saúde [internet]. 2018 [acesso em 2018 jan 5]. Disponível em: http://cnes2.datasus.gov.br/ Mod_Ind_Equipes.asp.

5. Shimizu HE, Fragelli TBO, Shimizu HE, et al. Competências Profissionais Essenciais para o Trabalho no Núcleo de Apoio à Saúde da Família. Rev Bras Educ Med [internet]. 2016 [acesso em 2018 jan 5]; 40(2):21625. Disponível em: https://doi.org/10.1590/1981$-52712015 \mathrm{v} 40 \mathrm{n} 2 \mathrm{e} 02702014$

6. Almeida ER. A gênese dos Núcleos de Apoio à Saúde da Família. Salvador: UFBA; 2016.

7. Campos GWS, Domitti AC. Apoio matricial e equipe de referência: uma metodologia para gestão do trabalho interdisciplinar em saúde. Cad. Saúde Pública. 2007; 3(2):399-407.

8. Campos GWS, Cunha GT, Figueiredo MD. Práxis e Formação Paideia: apoio e cogestão em saúde. São Paulo: Hucitec; 2013.

9. Nascimento DDG, Oliveira MAC. Análise do sofrimento no trabalho em Núcleos de Apoio à Saúde da Família. Rev da Esc Enferm da USP [internet]. 2016 [acesso em 2018 jan 5]; 50(5):848-54. Disponível em: https://doi.org/10.1590/s0080-623420160000600019.

10. Klein AP, d'Oliveira AFPL. O "cabo de força" da assistência: concepção e prática de psicólogos sobre o Apoio Matricial no Núcleo de Apoio à Saúde da Família. Cad. Saúde Pública [internet]. 2017 [acesso em 2018 jan 5]; 33(1):1-10. Disponível em: https://doi. org/10.1590/0102-311x00158815.

11. Correia PCI, Goulart PM, Furtado JP. A avaliabilidade dos Núcleos de Apoio à Saúde da Família. Saúde debate [internet]. 2017 [acesso em 2018 jan 5]; 41(esp):34559. Disponível em: https://doi.org/10.1590/0103$-11042017 \mathrm{~s} 25$.

12. Champagne F, Brousselle A, Contandriopoulos A-P, et al. A análise lógica. In: Avaliação: conceitos e métodos. Rio de Janeiro: Fiocruz; 2011. p. 105-14.

13. Champagne F, Brousselle A, Contandriopoulos A-P, Hartz Z. A análise estratégica. In: Avaliação: conceitos e métodos. Rio de Janeiro: Fiocruz; 2011. p. 95104.

14. Figueiró AC, Sóter AP, Braga C, et al. Análise da lógica de intervenção do Programa Nacional de Controle da Dengue. Rev Bras Saúde Matern Infant. 2010; 10(1):93-106.

15. Soares BC, Cardoso GCP, Figueiró AC. Análise estratégica da Vigilância Epidemiológica em tuberculose: uma experiência local. Saúde debate. 2017; 41(esp):22-33.

16. Campelo LM, Santos EM, Oliveira PTR. Análise estratégica do processo de formulação da PM\&A-SUS: lições aprendidas e desafios. Saúde debate. 2017; 41(esp):34-49.

17. Brasil. Diário Oficial da União $\mathrm{n}^{\circ} 183$ [internet]. 2017 [acesso em 2017 nov 20]. Disponível em: http://pesquisa.in.gov.br/imprensa/jsp/visualiza/index.jsp?d ata $=22 / 09 / 2017 \&$ jornal=1\&pagina $=71 \&$ totalArquiv os $=120$. 
18. Instituto Brasileiro de Geografia e Estatística. Informações completas, São Paulo [internet]. [acesso em 2017 jun 17]. Disponível em: https://cidades.ibge.gov. $\mathrm{br} / \mathrm{v} 4 / \mathrm{brasil} / \mathrm{sp} /$.

19. Minayo MCS, Assis SG, Souza ER. Avaliação por triangulação de métodos: Abordagem de Programas Sociais. Rio de Janeiro: Fiocruz; 2005.

20. Bauer MW, Gaskell G. Pesquisa Qualitativa com Texto, Imagem e Som: um Manual Prático. Petrópolis: Vozes; 2012.

21. Fontanella BJB, Ricas J, Turato ER. Amostragem por saturação em pesquisas qualitativas em saúde: contribuições teóricas. Cad. Saúde Pública. 2008; 24(1):1727.

22. Chizzotti A. Pesquisa em Ciências Humanas e Sociais. 11. ed. São Paulo: Cortez; 2010.

23. D’amour D, Sicotte C, Lévy R. L'action collective au sein d'équipes interprofessionnelles dans les services de santé. Sci Soc Sante [internet]. 1999 [acesso em 2017 nov 20]; 17(3):67-94. Disponível em: http://www.persee.fr/doc/sosan_0294-0337_1999_num_17_3_1468.

24. Tesser CD. Núcleos de Apoio à Saúde da Família, seus potenciais e entraves: uma interpretação a par- tir da atenção primária à saúde. Interface - Comun Saúde, Educ [internet]. 2016 [acesso em 2018 mar 19]; Disponível em: http://dx.doi.org/10.1590/180757622015.0939

25. Furtado JP, Onocko-Campos R. A transposição das políticas de saúde mental no Brasil para a prática nos novos serviços. Rev Latinoam Psicopatol Fundam. 2005; 8(1):109-22.

26. Brasil. Ministério da Saúde. Caderno de Atenção Básica N. 39: Núcleo de Apoio à Saúde da Família. Volume 1: Ferramentas para a gestão e para o trabalho cotidiano. Brasília, DF: Ministério da Saúde; 2014.

27. Bourdieu P. Algumas propriedades dos campos. In: Questões de Sociologia. Rio de Janeiro: Marco Zero; 1983.

28. Bourdieu P. A gênese dos conceitos de habitus e campo. In: O poder simbólico. Rio de Janeiro: Bertrand Brasil; 2001. p. 59-73.

\footnotetext{
Recebido em 10/09/2019

Aprovado em 07/05/2020

Conflito de interesses: inexistente

Suporte financeiro: não houve
} 